\title{
Patient with Morning Glory syndrome
}

\author{
Paciente com síndrome de Morning Glory
}

Thiago Gonçalves dos Santos Martins ${ }^{1}$, Diogo Gonçalves dos Santos Martins ${ }^{2}$, Ana Luiza Fontes de Azevedo Costa ${ }^{3}$

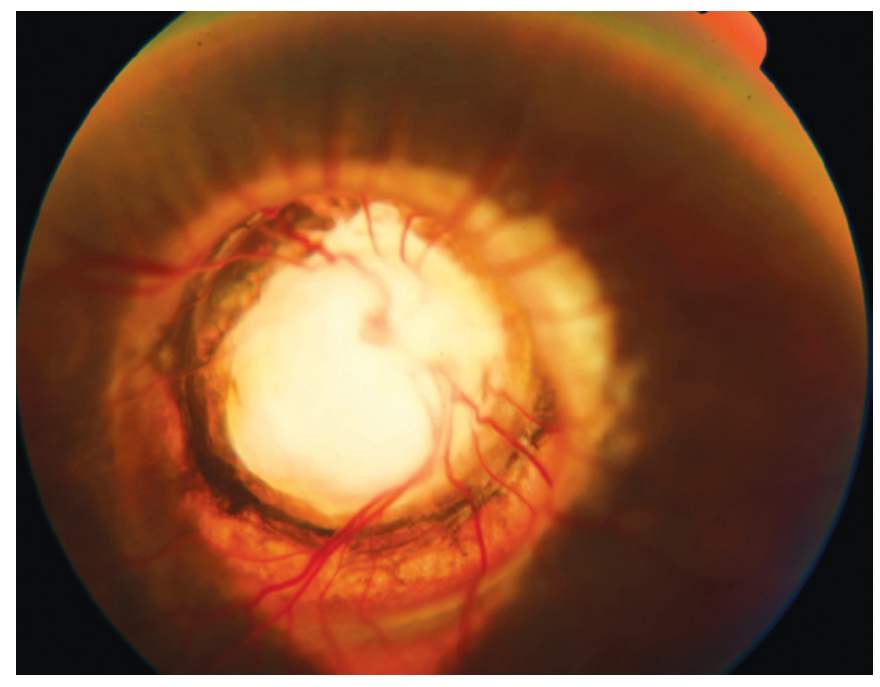

Figure 1. Optical nerve in fundus oculis

A 6-year-old patient was referred to our ophthalmology service because of an ocular deviation (esotropia) on the right eye for 3 years. Best-corrected visual acuity in right eye and 20/20 in left eye. According to the Krimsky test, the patient showed 15 prism dioptres esotropia in right eye. No changes were observed in biomicroscopy of both eyes and funduscopy of left eye was normal. An optical disc of increased size was seen in right eye, covered by glial tissue, rectified retinal vessels and with radial distribution. To confirm the diagnosis, we conducted an echography that showed typical sclerotic defect of Morning Glory syndrome, which is an increase of optic disc excavation and peripapilar retina (Figures 1 and 2).

The Morning Glory syndrome is a rare sporadic congenital anomaly, which is often unilateral. ${ }^{(1,2)}$ Bilateral

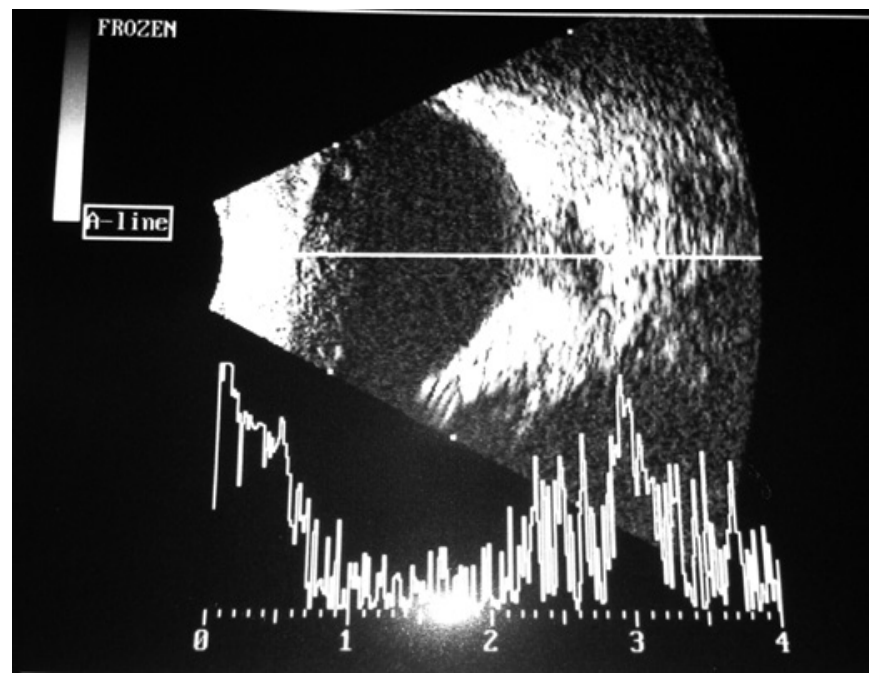

Figure 2. Ultrasonography confirming the diagnosis

cases are even rarer and can be hereditary. ${ }^{(2)}$ This syndrome was described by Kindler in 1970. The anomaly was termed Morning Glory syndrome because of its similarity to the tropical flower. This anomaly is characterized by increase in optical disk size with poor defined wedges and involved by pigmented ring, deep excavation, presence of glial tissue filling the optical disc and radial disposition of retinal vessels. ${ }^{(3)}$ Morning Glory syndrome increases the risk of serous retinal detachment and, in the first months/years of life can cause leucocoria.

Morning Glory syndrome can be associated to strabismus, cataract, nystagmus, coloboma of the crystalline and optic nerve drusen, ${ }^{(4,5)}$ as well as to anomalies of central nervous system, endocrine system,

\footnotetext{
1 Universidade Federal de São Paulo, São Paulo, SP, Brazil.

2 Universidade Estácio de Sá, Rio de Janeiro, RJ, Brazil.

${ }^{3}$ Hospital Federal dos Servidores do Estado, Rio de Janeiro, RJ, Brazil.

Corresponding author: Thiago Gonçalves dos Santos Martins - Universidade Federal de São Paulo, Rua Botucatu, 821, 2nd floor - Vila Clementino - Zip code:04023-062 - São Paulo, SP, Brazil Phone: (55 11) 5085-2010 - E-mail: thiagogsmartins@yahoo.com.br 
renal system and respiratory system. This syndrome rarely appears in black people, is twice more common in women than in men and no family heterogeneity is associated to it. ${ }^{(6)}$ Visual acuity is not always altered, and can be normal or compromised in different forms. Complications can appear such as serous retinal detachment (30\% of cases) and, more rarely, choroidal neovascularization. The syndrome is rarely associated with neurofibromatosis type $2 .^{(3)}$

The coloboma of optic disk, which is a differential diagnosis, is characterized as excavation, normally in inferior part, without glial tissue typically present in Morning Glory syndrome. ${ }^{(7)}$

\section{REFERENCES}

1. Kindler P. Morning glory syndrome: unusual congenital optic disk anomaly. Am J Ophthtalmol. 1970;69(3):376-84.

2. Kanski JJ. Malformações de desenvolvimento e anomalias. In: Kanski JJ. Oftalmologia clínica. 6a ed. Rio de Janeiro: Elsevier; 2008. p. 84-6.

3. Trabouisi El. Morning glory disc anomaly or optic disc coloboma. Arch Ophthtalmol. 1994;112(2):153.

4. Hodgkins P, Lees M, Lawson J, Reardon W, Leitch J, Thorogood P, et al. Optic disc anomalles and frontonasal dysplasia. Br J Ophthtalmol. 1998;82(3):290-3.

5. Shami M, Mc Cartney D, Benedict W, Barnes C. Spontaneus retinal reattachment in a patient with persistent hyperplastic primary vitreous and an optic nerve coloboma. Am J Ophthtalmol. 1992;114(6):769-71.

6. Stefko ST, Campochiaro P, Wang P, Li Y, Zhu D, Trabouisi El. Dominant inheritance of optic pits. Am J Ophthalmol. 1997;124(1):112-3.

7. Pollock $\mathrm{S}$. The morning glory disc anomaly:contractile movement, classification and embryogenesis. Doc Ophthtalmol. 1987;65(4):439-60. Review. 